Psychology, Evaluation, and Technology in Educational Research 2 (1), 2019, 10-21

Available Online: http://petier.org/index.php/PETIER

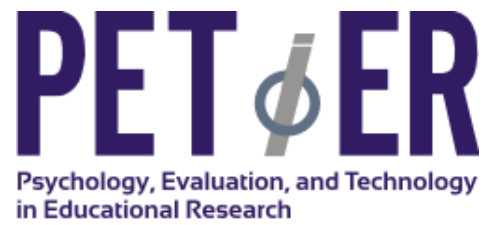
in Educational Research

\title{
Introducing career to kindergarten students
}

\author{
Rahajeng Bellinda Nastiti *, Edi Purwanta \\ Department of Guidance and Counseling, Program Pascasarjana, Universitas Negeri Yogyakarta \\ Jalan Colombo No 1, Karangmalang, Yogyakarta, 55281, Indonesia \\ * Corresponding Author. E-mail: rahajengbellindanastiti@gmail.com
}

Received: 14 September 2019; Revised: 18 October 2019; Accepted: 25 October 2019

\begin{abstract}
Career is a lifelong process that an individual will experience throughout his or her life. In relation to the statement, the study aims at depicting the development of career introduction into the Kindergarten Unit, namely in one of the kindergartens located in the City of Lubuklinggau, Province of South Sumatra. During the conduct of the study, the subjects that had been selected were 8 kindergarten students in the Nursery grade (two- to three-years old), 10 kindergarten students in the Kindergarten One Grade (three- to four-years old) and 2 classroom teachers. The type of the study was a qualitative study and the data were gathered by means of participatory observation. After the data had been gathered, the data were analysed by means of Miles \& Huberman qualitative data analysis model. After the study has been conducted, the results show that: (1) the Kindergarten Unit that has served as the research site already has thematic learning about career introduction; (2) the mechanism implementation of the thematic learning has not stimulated the career introduction to the students; (3) the material components of the career introduction have not been in accordance to the knowledge of the ideal career and the needs of the kindergarten students; (4) the readiness of the kindergarten teachers in preparing the learning materials has not been ideal; (5) there have been weaknesses on the media of career introduction which leads to the unideal situations among the kindergarten students; and (6) there should be school support toward the upgrade and the completeness of the thematic learning of the career introduction. Through the conduct of the study, it is expected that the mechanism of ideal career introduction in the school might stimulate information in accordance to the characteristics of the students so that the preferences toward the knowledge of career introduction might be early established for the next period.
\end{abstract}

Keywords: career introduction, kindergarten students, career guidance

How to Cite: Nastiti, R., \& Purwanta, E. (2019). Introducing career to kindergarten students. Psychology, Evaluation, and Technology in Educational Research, 2(1), 10-21. doi:http://dx.doi.org/10.33292/petier.v2i1.29

\section{INTRODUCTION}

Highly qualified career introduction starts from childhood since childhood is the essential period in the human life development (Xu, Hou, \& Tracey, 2014). Career development refers to the capacity of adopting certain career, which has been defined as the readiness of individual resources in dealing with every duty of career development in all development periods (Rivera \& Schaefer, 2009). In relation to the statements, kindergarten seems to be the most perfect and potential educational unit to start (Datar, 2006; Isaacs, Sawhill, \& Haskins, 2008). Therefore, the situations from the implementation mechanism of career education that has been oriented toward the childhood since in the kindergarten become important to expose. The results of a field observation in one of the kindergartens located in the City of Lubuklinggau, the Province of South Sumatera, show that career introduction has been implemented as part of 2013 Thematic Curriculum. Such early career introduction has been one of the efforts for developing the quality of career development. Then, the stages in the childhood are the ones of preparing the stage and opening the career construction (Hartung, 2016; Watson, 2016). The lifelong career approach (Super, 1975) states that career 
education or "occupational education" aims at directing the individuals toward the preferences of possible career and dynamic changes from the development of the surrounding environment in relation to the self-career development. Furthermore, the findings in the field show that the career introduction has been formulated on the themes of occupation through the inquiry learning model as the peculiar learning model that a school possesses; however, the implementation mechanism of career introduction in the school has not been ideal and effective. In line with these findings, the results of the observation in relation to the coverage of the children's situations show that the career introduction has been implemented to the students of Nursery Class (two-years to three-years old) and the students of Kindergarten One Class (three-years to four-years old). In addition, the results of the observation show that the students of the Nursery Class have not been able to state their dreams and have not also been able to identify the types of occupation around them. On the other hand, other results of the observation show that the students of Kindergarten One Class have been able to state their dreams and to identify general types of occupation that they have found in their surroundings; the occupations that the students of Kindergarten One Class have found are namely: doctor, policeman, pilot and firefighter. The female students of the Kindergarten One Class have even been able to state their dreams: they want to be the female cartoon figures from the movies like Princess and Frozen.

The lifelong career introduction that has been started form kindergarten holds the capacity of establishing the preliminary construction by means of exploration toward career knowledge, which stimulates the individual career alternatives that might be explored in the next stage of life. The more the career preferences that an individual has, the better the individual exploration will be in the next period of life in order to achieve the career satisfaction so that the mistakes and the grievance upon the wrong career preferences might be handled properly. In relation to the elaboration, Ginzberg states that lifelong career development refers to a process of attaining satisfaction by creating adjustment between individual preferences and environmental preferences (Paton \& McMahon, 2014). In relation to the implementation of career introduction, the findings in the field show that the career introduction has been less effectively implemented. The reason is that the implementation of the career introduction has been pursued only through the pictorial media that include: types of occupation and also tools and equipment of certain occupations. These pictorial media have been created by browsing the Internet and saving the pictures that have been found randomly and situationally as the learning materials. Then, the pictorial media have been devised by the teachers themselves in the form of A4 HVS print paper. Based on these findings, substantially the contents that have been used as the learning materials for the career introduction have not been based on the compatibility between the ideal materials that have been based on the theoretical reviews of career education approaches and the early developmental needs of the children. Furthermore, the functions of the pictorial media that have been designed have not effectively stimulated the provision of the information for the career introduction among the kindergarten students. One of the hindrances that lies behind the situation is that the media that have been compatible to the career knowledge and the early children development in the kindergarten are limited. The career introduction by means of the teacher-devised learning media becomes another obstacle for the teachers who do not have the vocational education background; consequently, this task has been juridically imposed to the teachers of Guidance and Counselling.

Another obstacle that the classroom teachers have been dealing with is the mastery of the capacity to create the learning situations of career introduction that are compatible to every stage of inquiry learning model as the peculiar learning model that the school has possessed. One of the requirements for the sufficient and well-stated readiness and also the competencies of the creative classroom teachers is being able to prepare the learning activities of career introduction so that the classroom teachers will be able to stimulate information, enthusiasm and active participation among the kindergarten students with regards to career introduction by enriching knowledge as the references or attaining the opportunities to improve the relevant skills in the form of, for example, training programs or seminar about early childhood and its developmental tasks. Therefore, the teachers in the kindergarten unit have complex challenges in stimulating the interesting information within the thematic learning and also in stimulating the interesting thematic learning itself.

Career refers to the decisions that an individual has made based on the subjective selfperception. Most of the time, individuals encounter the situations in which they should define their career alternative through the consideration of the self-compatibility in attaining the future life. Furthermore, Ginzberg states that the lifelong career development refers to the process of attaining 
satisfaction by making adjustment between the personal preferences and the environmental preferences (Patton \& McMahon, 2014). Indeed, career is personal decision but, in the reality, nowadays many people do not prefer that the career that they have defined in their childhood. In line with the statement, the results of a study by Trice \& McIan state that $23 \%$ respondents of $40-55$ years old develop the career that they have not thought or that they have not based on their own preferences (Auger, Blackhurst, \& Wahl, 2005).

According to (Spenner, Brown, \& Brooks, 1986), career preferences are not one-time event but, instead, career preferences consist of several decisions that have long-term implications for the sustainable career opportunities. The career period of childhood serves as the trigger for the career development periods that might influence the life-span development period and, in turn, this life-span development period might impact the career preferences that have been made during the adolescence and the adulthood. In line with the above elaboration, the findings from the study by (Hartung, Porfeli, \& Vondracek, 2005) reveal that the period of three years old-childhood serves as the preliminary career exploration period that has more focus on conscious, integrated and directed career exploration toward the future occupation. Departing from this statement, (Bryant, Zvonkovic, \& Reynolds, 2006) state that the core development in shaping the exploration toward the future career of the students is related to knowledge, belief and values of occupation.

Career has strong association with mastery of significant role of satisfying success in dealing with both the present life and the future life (Wahyuni, Nurdin, \& Bustamam, 2018). The incompatibility within the career preferences nowadays is influenced by the absence of early career introduction. Preparing career since early age by means of career introduction is an effort of introducing the career to the students. therefore, the kindergarten unit as the beginning of the formal education degree for the serves as the institution that stimulates the career introduction for the students. The establishment of the preliminary exploration results in the awareness, the expectation, the interest, the aspiration, the value and the capacity of adaption during the childhood and, in turn, the establishment facilitates the development of personal identity and the linkage to the individual social world.

Based on the results of the previous studies that have been elaborated, it is apparent that career introduction in the kindergarten unit as the a complex thematic learning process demands the teacher competencies that deal with the creation of learning situations that might stimulate learning information in relation to the characteristics of the kindergarten students. in addition, the compatible materials of career introduction should be based on the scientific domains of ideal vocational education. Career should be introduced in the early childhood since childhood is the essential period that develops the preliminary construction and provide preferences on the career knowledge among the kindergarten students, which will be useful to be explored in the next stage of life. ideally, the career of an individual refers to the compatibility of the individual's own preferences; however, most of the times individuals do not find the career that is compatible to their own perspective. The incompatibility of the career that has been developed might be related to the preferences of the learning experiences within the career introduction and the construction on the stimulation within the implementation of the career introduction that has been developed since the childhood in the kindergarten unit in relation to the career knowledge. Departing from the overall elaboration, through the study the researchers would like to identify the description of the implementation mechanism of career introduction in the kindergarten unit, specifically in one of the kindergarten units located in the City of Lubuklinggau, the Province of South Sumatera, that has already had the thematic learning of career introduction through inquiry learning model as the peculiar curriculum of the kindergarten unit.

\section{METHOD}

The approach that had been adopted in the study was the qualitative research. A qualitative research is conducted in order to attain the in-depth and meaningful data. Specific to the context of the study, the aim of the study was to attain the description and also the information of career introduction to the students in the kindergarten unit.

In gathering the data, the method that the researcher had implemented was observation. Observation refers to the process of attaining research data that involves the action of observing the people and the location during the conduct of the study in the field; within observation, the most 
important aspect is the observation process and the memorization. Then, observation consists of two types namely the participatory observation and the non-participatory observation. Specific to the conduct of the study, the researchers implemented the participatory observation; as a result, the researchers engaged themselves into the activities that both the classroom teachers and the students of the kindergarten unit under study performed during the learning process of career introduction. Within the observation, the data that had been gathered were the factual and accurate description and information about the aspects that the researchers should study with regards to the activities of both the classroom teachers and the students during the thematic learning of career introduction.

The conduct of observation includes the activities of observing an object by using all of the five senses. Observation might be performed by using sight, smell, voice, touch and taste. According to Spradley, the objects that are under observation during the conduct of a qualitative research consist of three important components namely place (the place of the social interaction that has been taking place), actor (the people who had been involved) and the activity (the activities that the actors perform within the social interaction that has been taking place). Specific to the context of the study, the three important elements might be elaborated as follows: (a) the place where the study had been taken place was one of the kindergarten units located in the City of Lubuklinggau, the Province of South Sumatera; (b) the actors within the conduct of the study were the classroom teachers, the students from Nursery Grade (two to three-years old students) and the students from Kindergarten One Grade (three to fouryears old students); and (c) the activities that had been observed within the conduct of the study were the learning process of career introduction. Substantially, the learning process of the career introduction for the kindergarten students consisted of the thematic learning situations with the themes of occupation that had been available in the kindergarten.

In more details, the subjects in the study were 8 students from Nursery Grade, 10 students from Kindergarten One Grade, 2 classroom teachers from Nursery Grade and another 2 classroom teachers from Kindergarten One Grade. Then, the location of the study was not specifically mentioned because the researchers would like to appreciate the research location since the kindergarten that served as the research location has been in existence and has become one of the most favourite kindergarten units in the City of Lubuklinggau.

In analysing the data that had been gathered, the researchers adopted the Miles and Huberman Model. According to the model, the data analysis within ta qualitative research is performed after the data have been gathered within certain period of time or until the data have been considered reliable or saturated. Within the context of the study, the data analysis was formulated by searching the data and arranging the data systematically through the field notes by using the words that had been collected into a widened text; thus, the data analysis would not involve statistical analysis as the data analysis tool.

Afterward, the data that had been attained from the field were classified into units and were inputted into patterns by means of data reduction. Bogdan (Sugiyono, 2013) states that the data analysis is performed by organizing the data, elaborating the data into units, synthesizing the data into patterns, selecting the data that are important and the data that will be studied and eventually drawing the conclusions that might be disseminated to others. In relation to the process, the data analysis proceeds to the data reduction or the data transformation after the field study has been completed. The objective of the data reduction was to classify and to select the main data and the important data in order to elicit the data and finally draw the final conclusions for the study. Later, the data that had been reduced provided clear, concrete and factual description and information with regards to the career introduction in the kindergarten unit during the thematic learning process in the classroom. In reducing the data, the researchers were guided by the objective of the study. After the data had been reduced, the researchers attained the analysis results and these results might be elicited further by means of brief description as part of data presentation so that the researchers might follow up the overall process until the submission of the final report on the study. As part of the final stage within the conduct of the study, the researchers should draw the conclusions and provide the verification on the consistency of the data that had been attained. The preliminary conclusions which had been unclear might be improved into more detailed conclusions with the supports from the valid evidence so that the credible final conclusions might be delivered. 


\title{
Psychology, Evaluation, and Technology in Educational Research, 2 (1), 2019, 14
}

\author{
Rahajeng Bellinda Nastiti, Edi Purwanta
}

\section{RESULTS AND DISCUSSIONS}

\section{Results}

Based on the observation that has been performed in the selected kindergarten unit located in the City of Lubuklinggau, the Province of South Sumatera, toward the students from both the Nursery Classroom (two to three-years old) and tjhe Kindergarten One Classroom (three to four-years old), the researchers gather several findings with regards to the career introduction among the students. The findings from the field observatioln toward the implementation of thematic learning for the career introduction will be elaborated in Table 1 .

Table 1. Findings from theField Observation

Aspects Under Observation
Career Introduction in The-
matic Learning of 2013
Curriculum for Kindergar-ten
Unit

Components of Career Introduction in the Thematic Learning Materials of "Occupation" within the Classroom

Inquiry Learning Model in the theme "Occupation" as the Teaching Method of the Classroom Teachers
Results of Observation

- Departing from the results of field observation, it is found that the kindergarten unit in the City of Lubuklinggau has already had the thematic learning in relation to career introduction; the thematic learning has been specifically formulated under the theme "Occupation." The conduct of thematic learning in the 2013 Curriculum with regards to occupation refers to the spirit of supporting the national objectives in order to generate the golden generation since the early period at the level of kindergarten unit. Therefore, in the same time the results of the field observation show that the kindergarten unit that has been selected as the research site in the City of Lubuklinggau has implemented the thematic learning that goes in accordance to the spirit of 2013 Curriculum, namely to support the national objectives of the curriculum implementation. In other words, it might be asserted that the learning theme "Occupation" might be considered as the effort of providing early stimulation so that the individual development might be pursued in the childhood by attaining and holding the career preferences as early as possible since childhood is the most appropriate period for constructing the career development.

- Furthemore, the findings from the field observation show that the career introduction that has been formulated through the theme "Occupation" has been implemented in Nursery Grade (containing two to three-years old students) and in Kindergarten One Grade (containing three to four-years old students).

- The results of the field observation show that the career introduction that has been formulated in the thematic learning about occupation has been implemented in Nursery Grade and the Kindergarten Grade from the kindergarten unit that has been selected in the City of Lubuklinggau. The thematic learning materials that have been explained by the teachers include: (1) types of occupation; (2) roles of occupation; (3) tools of occupation; and (4) place of occupation.

- The learning method that has been implemented in the Nursery Grade and the Kindergarten One Grade is the Inquiry Learning Model and the use of the Inquiry Learning Model is adjusted to the theme "Occupation" under the following sequence: (1) inquiry-in stage, which consists of orientation, observation and preliminary knowledge of the students with regards to the theme "Occupation"; (2) finding out stage, which consists of question-andanswer sessions and students' curiosity with regards to the theme "Occupation"; (3) sorting-out stage, which consists of discussion sessions about the theme "Occupation" within the classroom; (4) going-further stage, which consists of information components and their provision to the students in the classroom with regards to the theme "Occupation" by means of pictorial-based lecturers under the following aspects: (a) types of occupation; (b) roles of occupation; (c) tools of occupation; and d) sites of occupation; (5) making conclusions; and (6) taking action. Both Making Conclusions and Taking Actions are the stages in which the classroom teachers repeat the learning materials about "Occupation" that have been explained previously and provide opportunity for the students to explain again the theme "Occupation" according to their own perspective and language independently 
Psychology, Evaluation, and Technology in Educational Research, 2 (1), 2019, 15

Rahajeng Bellinda Nastiti, Edi Purwanta

Aspects Under Observation

Teaching Materials of Career Introduction under the Theme "Occupation"

Performance of Classroom Teachers

School Availability in Facilitating the Thematic Learning under the Theme "Occupation"
Results of Observation

in accordance to the information that has been provided as follows: (a) types of occupation; (b) roles of occupation; (c) tools of occupation; and (d) sites of occpation.

- From the results of the field observation toward the Nursery Grade and the Kindergarten One Grade in the Inquiry Stage, it is found that the orientation, the preliminary knowledge and the information among the students with regards to occupation have been low. Consequently, in the Finding-Out Stage and the Going-Further Stage the theme "Occupation" becomes a peculiar challenge for the classroom teachers in stimulating and informing the learning materials of occupation clearly.

- The teaching materials have been designed directly by the classroom teachers in the form of HVS A4-based printed-pictures and these pictures are laminated in order to be used as the teaching materials for the career introduction under the theme "Occupation" in both the Nursery Grade and the Kindergarten One Grade. Each paper contains a wide-sized picture that depicts the type, the role, the tool and the site of the given occupation.

- The findings in the Nursery Grade show that the pictorial media that have been utilized in the Going-Further Stage draw less enthusiasm among the students. The reason is that the pictorial media have served as the only information media within the thematic learning of career introduction in the classroom.

- On the other hand, the findings in the Kindergarten One show that the pictorial media that have been utilized in the Going-Further Stage draw higher enthusiasm and more active response among the students although the pictorial media have served as the only information media within the thematic learning of career introduction in the classroom.

- Furthermore, the findings from the field observation show that in the Taking Action Stage within the Kindergarten One Grade the classroom teachers have modified the thematic learning of career introduction by implementing the role model method through the utilization of several professional uniforms such as doctor, nurse and policemen. Later, in this occasion the students are invited to explain the types, the roles, the tools and the sites of these occupations. The students might use the HVS A4-sized printed-pictures that have been laminated in providing their explanation. The utilization of the professional uniforms has been able to elicit more enthusiasm among the students.

- With regards to both of the Nursery Grade and the Kindergarten One Grade, the findings of the field observation show that the classroom teachers have not maximally prepared the learning material of career introduction. The less maximum preparation has been shown by the situational preparation that the classroom teachers have made both prior to and during the thematic learning process. As a result, the quality of the information delivery has been less optimum.

- With regards to the school availability in facilitating the source of teaching materials, the findings of the field observation imply that the school should upgrade and complete the source so that the teaching-learning process will be more interesting for the students. The visual media-based print media for the learning material supports in the form of books, pop-art books or cards in relation to the themes of career introduction should be afforded so that the teachers might expand their preferences in both designing various learning methods and in attaining numerous teaching materials. Thereby, the enthusiasm and the participation of the students in attending the learning process by means of interesting pictorial media might be improved and thus the learning process will be more enjoyable for the students. Furthermore, the availability of learning materials, learning media or learning cards about career introduction might facilitate the students to attain concrete description over the visualized images so that the students will have more optimum and more impressive information stimulation of their career introduction. 
Psychology, Evaluation, and Technology in Educational Research, 2 (1), 2019, 16

Rahajeng Bellinda Nastiti, Edi Purwanta

\section{Discussions}

The issues in relation to the global career development might not be separated from the individual life since the career development plays significant role for both the future success and the individual welfare. The appropriate career development starts from childhood because childhood is the appropriate period for constructing the career and the career construction in the childhood will influence the career maturity of the children in the future. Therefore, the mechanism of career introduction in the childhood is highlighted as an essential material. With regards to the career orientation in the childhood, the findings in the field show that the career introduction has been implemented in the selected kindergarten unit as part of the 2013 Thematic Curriculum through the inquiry learning model; however, the implementation of the career introduction has not been optimum. These findings are supported by the results of other studies (for example: (Rivera \& Schaefer, 2009)), which show that career introduction has been implemented since the school age in Italia. Furthermore, the findings in the observation also show that the preliminary career knowledge of the children prior to the provision of career introduction has been limited to the phantasy-type and the general-type occupation. Consequently, it should be asserted that career development is a lifelong process that should be undergone throughout the life span, which starts from the childhood (Donald et al., 1975). In relation to the statement, (Super, 1975) explains that vocational education facilitates the compatibility between the self-preferences and the dynamic environmental situations that accompany the individual life and also between the self-preferences and the role in the school environment, the family environment and the surrounding environment in order to achieve the satisfying career maturity for the future of the individual.

The mechanism of attaining career satisfaction should be attained from the childhood; since this period, the career satisfaction should be explored by means of stimulation toward career introduction in the kindergarten. Career exploration thus refers to the activities of gathering relevant information with regards to the progress of individual career (Sawitri \& Dewi, 2015). Furthermore, (Denault, Ratelle, Duchesne, \& Guay, 2019) states that career exploration refers to the self-understanding such as interest and capacity and relevant information gathering activities with regards to the opportunities and the obstacles in numerous environmental contexts such as school, occupation and social network. according to (Rivera \& Schaefer, 2009), career introduction in the childhood will influence the career preferences in the future; therefore, career introduction might be beneficial for serving as the foundation for both the parents and the teachers in directing and facilitating the career that will support the children's career in the future. Departing from these reviews, it might be defined that as a school institution kindergarten has been the most appropriate institution for facilitating the developmental aspects of the students through the experience of exploring the students' potentials as unique individuals.

One of the developmental aspects which manifestation has been pursued through the implementation of 2013 Curriculum is career introduction, which has bee formulation through the themes of occupation with the following material coverage: types of occupation, role of occupation, tools of occupation and locations of occupation. The findings from the field observation show that the less active enthusiasm and participation from the children in the classroom and this might be one of the indicators that the stimulation of career introduction has not been optimally delivered. Then, the obstacles that have been found in the field show that the implementation of career introduction among the kindergarten students become a peculiar challenge for the teachers especially with regards to the efforts of pursuing and improving the quality of the teacher performance in preparing the interesting thematic learning for the career introduction since the interesting thematic learning will draw the students' enthusiasm and thus will result in the active participation among the students; consequently, the teachers should be able to stimulate the career introduction well in accordance to the developmental age of the kindergarten students. Furthermore, the findings in the field show that the teachers' decision with regards to the material coverage for the implementation of the career introduction to the students has not been based on the theories of ideal career introduction and the compatibility to the developmental age of the students; consequently, the thematic learning process of the career introduction suffers from several obstacles such as the less optimum enthusiasm and the less active participation among the students. The intended coverage of learning materials for the career 
introduction above include the types, the roles and the tools of occupation that should be explained in adjustment to the development of the early children's capacity.

The uncertainty over the substantial coverage of ideal learning materials for the career introduction among the kindergarten students is the fundamental point of departure for stimulating the accurate information of career introduction so that career introduction might be easily understood as new information that draws the curiosity of the students and might impact the quality of the learning process for the career introduction in the classroom. One of the challenges that the kindergarten unit classroom teachers have is that the classroom teachers come from various educational backgrounds. The findings from the field observation in the selected kindergarten unit show that the educational background of the teachers in Nursery Classroom and in the Kindergarten One Classroom has been dominated by English Department; the consequence is that the learning materials for the career introduction that are in accordance to the theory of vocational education and the developmental age of the early children have not been uniform with regards to the ideal learning materials for the thematic learning of career introduction. Furthermore, the challenges that the kindergarten teachers have is that the teachers should attain further higher competences in operationally preparing the lesson plans. One of these competences is preparing the learning materials that serve as the information media. In addition, the teachers' creativity in relation to the utilization or the design of the career introduction learning media might influence the learning process quality so that the active participation and the optimum enthusiasm in the classroom might be attained. The use of occupational uniform by the teachers of Kindergarten One as the media for career introduction has been effective in eliciting the students' enthusiasm and participation. Unfortunately, the teachers have not been completely prepared and this incomplete preparation has resulted in their obstacle to internalize the information of career introduction in the classroom. Situationally, the classroom teachers' preparation in implementing career introduction has been shown by displaying the occupation themes over the A4-sized learning media; as a result, the students' enthusiasm becomes lower. Despite the obstacle, the findings from the field observation show that the classroom teachers who wear the occupational uniform as part of their improvisation in implementing the career introduction have successfully drawn the interest and the enthusiasm of the students.

The school, in this case the selected kindergarten unit, might facilitate the thematic learning process of career introduction by providing the necessary media so that these media might be benefitted and be modified by the teachers in designing the interesting learning media for the students. Through the interesting media, the introduction of numerous careers toward the students might impact the students' career preferences in the form of career knowledge; consequently, the students will attain optimum career learning within the career introduction. The type of media that serves as the information for the career introduction contributes to the creation of enjoyable learning atmosphere within the implementation of career introduction and, in the same time, the active participation among the students during the learning process. Unfortunately, based on the findings that have been elaborated, it might be concluded that the efforts of attaining the support media that serve as the information media for the career introduction in accordance to the developmental age of the children have been limited and unideal. Consequently, the limited availability of the support media for the thematic learning process of the career introduction in the classroom contributes to the less optimum stimulation of information with regards to the interesting career introduction whereas the service media of career introduction contributes to the enrichment of career exploration during the childhood through the career preferences that go in accordance to the developmental age of the kindergarten students. In line with the results of the study that have been elaborated, (Zikic \& Hall, 2009) states that the efforts of career exploration that have been planned result in positive career results.

The availability of the career introduction learning media might be considered as one of the efforts for overcoming the learning obstacles so that the teachers might deliver the enjoyable preliminary learning experience of career introduction for the kindergarten students. According to King \& Multon, career introduction that has been conducted by means of learning media might influence the children's understanding and target toward the career development based on the personal characteristics of the children (Hartung, 2013). Trice-Camp and Rush specifically state that since the age of four years old the children start to frame their ideas and assessments about the compatibility of numerous types of occupation for their own aspiration. Thus, the career introduction is useful in assisting both the prediction and the identification of the career preferences for the children's career in 
Psychology, Evaluation, and Technology in Educational Research, 2 (1), 2019, 18

Rahajeng Bellinda Nastiti, Edi Purwanta

the future (Anwar, 2017). Career development is an integral part of the students' academic and sociopersonal aspects in meeting their needs within the domain of career preferences; consequently, it should be admitted that career introduction becomes an important responsibility for the counsellors of professional schools.

The reviews toward the findings that have been gathered form the field observation in the above elaboration depict that the classroom teachers, the schools and the developers in the scientific domain of career education, which in terms of curriculum belongs to the domain of Guidance and Counselling, hold continuous responsibility in overcoming the obstacles in the thematic learning process of career introduction in accordance of the developmental age of the kindergarten students. Career development in the childhood has been an interesting focus at least in the level of field research since most attentions have been placed in the main transitional points such as the entrance to universities or the entrance to workmanship (Patton, 2017). Career introduction in the childhood thus becomes an important component that should be given attention. The results of a study by (Ebenehi, Rashid, \& Bakar, 2016) show that the absence of career introduction in the childhood might impact the establishment of the career that will be undergone. Furthermore, through the results of his study (Ebenehi et al., 2016) states that 33\% university students in Nigeria demand attention on the career exploration as their orientation toward understanding their own personality and environment, which hold the control over the decision on the future career aspects such as: awareness on personal interest, skills, competences, values, work preferences and work environment. The implementation of learning process on the career introduction since the childhood will better direct and establish the future that the children will undergo. The initiatives in the childhood with regards to the employment might be a pioneer in terms of adolescent career development and employment exploration in the future by expanding the career understanding in the period of elementary, junior and senior high school; in turn, this expansion will bring about positive impact on the establishment of the future career (Howard \& Walsh, 2011). Furthermore, (Zikic \& Hall, 2009) state that career exploration might be defined as a lifelong process that specifically leads to the transition in each stage of individual life and involves the activities of gathering information with regards to personality and environment so that individuals might plan and define their career that will lead to the personally meaningful life for the individuals. Departing from the above explanation, it is clear that career exploration is a process that takes time; during this process, individuals tend to be more aware in relation to their like and dislike and also to be more focused on the exploration toward the specific domain.

The importance of career development and life design in the preliminary years should be discussed with focus on the developmental tasks that should be accomplished successfully in the childhood. Eventually, the objective of pursuing the career development and the life design is to prepare the young generation to manage the complexity in the progress of their career and its related transition not only in the preliminary years but also in the lifelong sequence. (Ebenehi et al., 2016) states that the researchers of career domains have adopted the capacity of career adaptation. The career preparation in childhood indeed has significant influence on the success of the children in the future. With regards to the statement, career adaptation refers to the psychosocial construction that includes the preparation and the resources for successfully accomplishing the vocation tasks, the job transition and the unexpected challenge. In relation to the statement, (Maree, 2018) adds that there have been relatively few studies on the career development and the life design in the preliminary years of an individual especially in the context of developing countries. Therefore, the theoretical model that becomes the basis of the career development should be revisited by means of discussion over the theories of life design counseling.

Sawitri and Dewi (2015) state that in order to teach career there should be the media that serve as the support for the conduct of successful learning system. In the context of the study, the media that have been utilized is the Map Mapping Media; Map Mapping Media refer to the learning media that have been designed in order to facilitate the students in planning their career through the figures of mind map that the students have drawn in accordance to their own talent and interest. The improvement on the career planning capacity after the Map Mapping Media have been utilized is already apparent within the results of the study. In the beginning of the study, most of the students belong to the "Very Low" criteria with the number of respondents 40 people $(69 \%)$. After the Cycle I has been implemented, the career planning capacity has improved since there have not any been any students that belong to the "Very Low" category $(0 \%)$ and most of the students belong to the "High" 
category (27 students or 47\%). Next, after the Cycle II has been implemented, the career planning capacity has improved further and 58 students $(100 \%)$ belong to the "Very High" category. As a result, the conduct of the study should be stopped in Cycle II since the indicators of success have been met. These results suit well into the argument by Hanani (2013), who states that career introduction for the elementary school students is highly important in order to support the success of the children's career in the future. Furthermore, Hanani explains that career card might be utilized as the career guidance media that are compatible to the characters of the elementary school students. In the context of this study, the career card as the career guidance media have been considered feasible based on the results of the material expert test and the media expert test. The results of the media expert test that consists of 19 items with regards to content feasibility, language, presentation and objective of career guidance show that the career card has been good and feasible for implementation. Similarly, the results of the material expert test that consists of 47 items with regards to graphic design layout, package physical layout, package graphic physucal layout, physical layout, userfriendliness, consistency, artistic formation, usefulness, support power, directions of use and producer logo show that the career card has been good and feasible for implementation as well. In line with these statements, Praditya (2017) state that the pop-up media of career introduction has met the criteria of feasibility. The score implied by the media expert test results is $91 \%$ and the score implied by the material expert test results is $92 \%$; meanwhile, the score implied by the user candidates is $96 \%$. Therefore, in overall the mean score of the career card is $93 \%$ with the category "Very Good, No Further Revision." Therefore, it might be concluded eventually that the pop-up media of career introduction has already met the aspect of feasibility for implementation among the Grade III Students of Tambakagung Public Elementary School in Puri, Mojokerto.

\section{CONCLUSIONS}

Based on the findings in the field, it might be concluded that the orientation of the career introduction in the childhood that has been formulated nationally is implemented through the conduct of Thematic Learning in the 2013 Curriculum under the theme "Occupation" in the kindergarten units. The mechanism of career introduction in the kindergarten unit has been well-implemented but there are still several points that should be highlighted. Departing from the results of the field observation, the mechanism of career introduction has not been compatible to the scientific domain of ideal career education and the developmental needs of the kindergarten unit students. Then, the obstacles within the implementation of thematic learning for the career introduction are namely: (1) the demand to develop enthusiasm and active participation among the students during the career introduction in the classroom; (2) the demand to master the capacity in stimulating the information of career introduction in the classroom; and (3) the demand to have well-qualified instead of situational preparation for the materials of career introduction. Then, the decisions made by the classroom teachers with regards to the coverage of the career introduction materials as part of career information have been formulated under the following aspects: (1) types of occupation; (2) role of occupation; (3) tools of occupation; and 4) sites of occupation. Unfortunately, the decisions that have been made are not yet compatible to the theory of career introduction and also to the characteristics and the needs of the developmental age among the kindergarten students. Not to mention, the kindergarten unit under study has suffered from limited learning media that might support the learning process of career introduction that the students need.

Despite the discussions and the conclusions in the study, it is expected that the results of the field observation within the study might serve as a description for the obstacles that might be found within the implementation of thematic learning for career introduction so that the orientation for the implementation of career introduction might be well-implemented and in compatibility with the science of vocation education for childhood. Furthermore, it is also expected that the results of the study might be benefial as part of career introduction for the practitioners on the level of kindergarten unit with regards to the phenomena that have been studied. In addition, the implication of the study is expected to overcome several obstacles that have come to the surface with regards to the thematic learning of career introduction through the development of several support media as the learning sources that might accompany the ideal conduct of career introduction in accordance to the science of 
vocation education so that the conduct of the career introduction mgiht be accurate for the developmental tasks of the kindergarten students.

\section{REFERENCES}

Anwar, M. K. (2017). Pengembangan buku kerja eksplorasi karier pada siswa Sekolah Menengah Pertama Ali Maksum Bantul. Universitas Negeri Yogyakarta.

Auger, R. W., Blackhurst, A. E., \& Wahl, K. H. (2005). The development of elementary-aged children's career aspirations and expectations. Professional School Counseling, 8(4), 322-329.

Bryant, B. K., Zvonkovic, A. M., \& Reynolds, P. (2006). Parenting in relation to child and adolescent vocational development. Journal of Vocational Behavior, 69(1), 149-175. https://doi.org/10.1016/j.jvb.2006.02.004

Datar, A. (2006). Does delaying kindergarten entrance give children a head start? Economics of Education Review, 25(1), 43-62. https://doi.org/10.1016/j.econedurev.2004.10.004

Denault, A.-S., Ratelle, C. F., Duchesne, S., \& Guay, F. (2019). Extracurricular activities and career indecision: A look at the mediating role of vocational exploration. Journal of Vocational Behavior, 110, 43-53. https://doi.org/10.1016/j.jvb.2018.11.006

Ebenehi, A. S., Rashid, A. M., \& Bakar, A. R. (2016). Predictors of career adaptability skill among higher education students in Nigeria. International Journal for Research in Vocational Education and Training, 3(3), 212-229. https://doi.org/10.13152/IJRVET.3.3.3

Hartung, P. J. (2013). The life-span, life-space theory of careers. In S. D. Brown \& R. W. Lent (Eds.), Career Development and Counseling: Putting Theory and Research to Work. https://doi.org/10.1021/cm070324n

Hartung, P. J. (2016). Childhood: Career construction's opening act. In Career Exploration and Development in Childhood (pp. 38-47). Routledge.

Hartung, P. J., Porfeli, E. J., \& Vondracek, F. W. (2005). Child vocational development: A review and reconsideration. Journal of Vocational Behavior, 66(3), 385-419. https://doi.org/10.1016/j.jvb.2004.05.006

Howard, K. A. S., \& Walsh, M. E. (2011). Children's conceptions of career choice and attainment: Model development. Journal of Career Development, 38(3), 256-271. https://doi.org/10.1177/0894845310365851

Isaacs, J. J., Sawhill, I. V. I., \& Haskins, R. (2008). Getting ahead or losing ground: Economic mobility in America. Brookings Institution.

Maree, J. G. (2018). Promoting career development and life design in the early years of a person's life. Early Child Development and Care, 188(4), 425-436. https://doi.org/10.1080/03004430.2017.1345892

Patton, W. (2017). Career adaptability, employability and resilience for children in the early school years. In Psychology of Career Adaptability, Employability and Resilience (pp. 207-223). https://doi.org/10.1007/978-3-319-66954-0_13

Patton, W., \& McMahon, M. (2014). Career development and systems theory. https://doi.org/10.1007/978-94-6209-635-6

Rivera, L. M., \& Schaefer, M. B. (2009). The career institute. Journal of Career Development, 35(4), 406-426. https://doi.org/10.1177/0894845308327737

Sawitri, D. R., \& Dewi, K. S. (2015). Academic fit, adolescent-parent career congruence, and career exploration in university students. Procedia Environmental Sciences, 23, 105-109. https://doi.org/10.1016/j.proenv.2015.01.016

Spenner, K. I., Brown, D., \& Brooks, L. (1986). Career choice and development. Contemporary Sociology, 15(1), 126. https://doi.org/10.2307/2070975

Super, D. E. (1975). Career education and career guidance for the life span and for life roles. Journal of Career Development, 2(2), 27-42. https://doi.org/10.1177/089484537500200204

Wahyuni, C. L., Nurdin, S., \& Bustamam, N. (2018). Kematangan karir siswa SMA Negeri 1 Bandar 
Psychology, Evaluation, and Technology in Educational Research, 2 (1), 2019, 21

Rahajeng Bellinda Nastiti, Edi Purwanta

Dua Pidie Jaya. JIMBK: Jurnal Ilmiah Mahasiswa Bimbingan \& Konseling, 3(4). Retrieved from http://www.jim.unsyiah.ac.id/pbk/article/view/5006

Watson, M. (2016). Career exploration and development in childhood. https://doi.org/10.4324/9781315683362

Xu, H., Hou, Z.-J., \& Tracey, T. J. G. (2014). Relation of environmental and self-career exploration with career decision-making difficulties in Chinese students. Journal of Career Assessment, 22(4), 654-665. https://doi.org/10.1177/1069072713515628

Zikic, J., \& Hall, D. T. (2009). Toward a more complex view of career exploration. The Career Development Quarterly, 58(2), 181-191. https://doi.org/10.1002/j.2161-0045.2009.tb00055.x 